\title{
A prospective study on the changes and clinical significance of pre-operative and post-operative circulating tumor cells in resectable gastric cancer
}

Qiyue Zhang ${ }^{1 \dagger}$, Fei Shan ${ }^{2 \dagger}$, Ziyu Li ${ }^{2}$, Jing Gao ${ }^{1}$, Yilin Li ${ }^{1}$, Lin Shen ${ }^{1}$, Jiafu $\mathrm{Ji}^{2^{*}}$ and Ming Lu ${ }^{1 *}$ (D)

\begin{abstract}
Background: Circulating tumor cells (CTCs) have been suggested as potential prognostic indicators for multiple tumors, including gastric cancer; however, pre- and post-operative CTC changes in resectable gastric cancer and possible correlations to post-operative recurrence have not been evaluated.

Methods: Subjects ( $n=93$ ) with resectable gastric cancer were prospectively reviewed from July 2013 to December 2014 at Peking University Cancer Hospital. The proportion of CTCs were evaluated before $(n=93)$ and after $(n=63)$ radical operation using a standardized CellSearch system.

Results: CTCs $\geq 1$ were measured in the pre-operative blood of 31 (33.3\%) patients and in the post-operative blood of 21 patients (33.3\%). Patients with relatively poor clinicopathological features had more pre- and post-operative CTCs. The 3-year disease-free survival (DFS) rate for patients with CTCs $\geq 5 / 7.5 \mathrm{ml}$ was significantly lower than for patients with CTCs $<5 / 7.5 \mathrm{ml}$ (40.0\% vs $66.4 \%, \mathrm{p}<0.001$ for pre-surgery; $25.0 \%$ vs $62.2 \%, \mathrm{p}<0.001$ for post-surgery). Patients with CTCs $\geq 5 / 7.5 \mathrm{ml}$ in post-operative blood had significantly shorter mean DFS (1.28 vs 31.6 months; $p=0.002$ ) and overall survival (OS; 10.0 vs 34.9 months; $p=0.001$ ) than other patients. Among the 10 patients with hematogenous recurrence, 3 had post-operative CTCs $\geq 2 / 7.5 \mathrm{ml}$ and had early recurrence (DFS 1.1, 1.1, 1.4 months). Moreover, DFS for the seven patients was 20.2, 11.9, 20.0, 6.0, 15.5, 25.9, 30.0 months, respectively. DFS for the three patients with increased CTCs after surgery was shorter than for patients with mildly increased, stable, or decreased CTCS.
\end{abstract}

Conclusions: Pre- and post-operative CTCs are promising prognostic markers for resectable gastric cancer. Our study further suggests that increased post-operative CTCs may be correlated with hematogenous recurrence.

Trial registration (ClinicalTrials.gov Identifier: NCT01848015). Registered 7 May 2013. https:/clinicaltrials.gov/ct2/show/ NCT01848015

Keywords: CellSearch, Circulating tumor cells, Hematogenous metastasis, Recurrence, Resectable gastric cancer

\footnotetext{
*Correspondence: jiafuj@hotmail.com; qiminglu_mail@126.com

${ }^{\dagger}$ Qiyue Zhang and Fei Shan are co-first authors

1 Key Laboratory of Carcinogenesis and Translational Research (Ministry

of Education/Beijing), Department of Gl Oncology, Peking University

Cancer Hospital \& Institute, Fucheng Road 52, Haidian District,

Beijing 100142, China

2 Key Laboratory of Carcinogenesis and Translational Research (Ministry of Education/Beijing), Department of Surgery, Peking University Cancer Hospital \& Institute, Fucheng Road 52, Haidian District, Beijing 100142, China
}

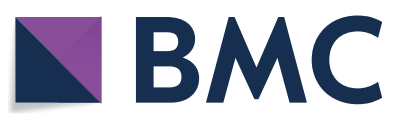

(c) The Author(s) 2018. This article is distributed under the terms of the Creative Commons Attribution 4.0 International License (http://creativecommons.org/licenses/by/4.0/), which permits unrestricted use, distribution, and reproduction in any medium, provided you give appropriate credit to the original author(s) and the source, provide a link to the Creative Commons license, and indicate if changes were made. The Creative Commons Public Domain Dedication waiver (http://creativecommons.org/ publicdomain/zero/1.0/) applies to the data made available in this article, unless otherwise stated. 


\section{Background}

Gastric cancer is a highly malignant disease, with high morbidity and mortality rates worldwide, especially in China [1]. Surgery is the most common curative approach for resectable gastric cancer; however, many patients, especially those with local advanced gastric cancer suffer from recurrence after radical gastrectomy, contributing to poor prognosis [2, 3]. Presently, poor clinicopathological characteristics (such as TNM classification, depth of tumor penetration, and lymph node metastasis) and high carcinoembryonic antigen (CEA) are predictive of high-risk post-operative tumor recurrence; but their use is limited due to low specificity and accuracy [4-7]. In addition to predicting patient prognosis, monitoring recurrence patterns of gastric cancer patients is vital. Hematogenous distant metastasis is a chief pattern of recurrence for gastric cancer patients. Yoo and colleagues confirmed that the mean time for hematogenous recurrence was the shortest [8]; however, TNM classification could not predict recurrence patterns of gastric cancer accurately. Therefore, the identification of effective markers is necessary to predict disease recurrence.

Circulating tumor cells (CTCs) are important markers of malignant tumor metastasis $[9,10]$ that can predict chemotherapeutic response and prognosis for multiple metastatic tumors [11-17]. In addition, pre- or postoperative CTCs have been reported to be correlated to post-operative recurrence of bladder, prostate, breast, and colorectal cancers, but data reported differ among studies [18-22]. Gazzaniga's group reported that CTCs may predict decreased time to first tumor recurrence for stage I bladder cancer [21], but Pal and colleagues reported no correlation existed between CTCs and tumor recurrence for prostate cancer [22].

Correlations in pre- or post-operative CTCs to postoperation recurrence and prognosis for gastric cancer are also limited. Uenosono and colleagues analyzed CTCs in pre-operative peripheral blood samples of 148 patients who underwent gastrectomy, and intact CTCs in preoperative blood were significantly correlated with poor clinicopathological characteristics (depth of tumor invasion, lymph node metastasis, etc.) [23]. In addition, relapse-free and overall survival for patients with CTCs was significantly lower than for patients without CTCs $(p<0.001)$ [23]. Of note, pre-operative CTCs was an independent factor for overall survival (OS) for patients with gastric cancer according to multivariate analysis $(\mathrm{p}=0.024)$. However, whether post-operative CTCs and changes in CTCs during surgery could be assessed for resectable gastric cancer (stage I-III) and any correlations with prognosis is unclear. Thus, we conducted this prospective study (ClinicalTrials.gov Identifier: NCT01848015), and measured CTCs in pre- and post-operative blood from patients with resectable gastric cancer and analyzed correlations of pre- and postoperative CTCs and further evaluated changes in CTCs during surgery with clinicopathological characteristics, prognosis, and recurrence patterns.

\section{Methods \\ Patients and sample collection}

From July 2013 to December 2014, 93 subjects with histologically confirmed gastric cancer who underwent a radical gastrectomy at the Department of Surgery in Peking University Cancer Hospital were enrolled. All of the patients were diagnosed with stage I-III gastric cancer. We excluded patients with distant metastases or those had undergone therapy prior to surgery, and 63 subjects had paired preoperative and postoperative blood samples. Peripheral blood was sampled within 1 week prior to surgery and post-operative samples were acquired a week after surgery. CTCs were counted for all of the subjects.

\section{Isolation and enumeration of circulating tumor cells}

Circulating tumor cells were counted with a CellSearch system (Veridex, New Jersey, U.S.) according to previously published methods [17], which included a CellSearch Epithelial Cell Kit, CellPrep System, and CellSpotter Analyzer. In brief, $7.5 \mathrm{ml}$ blood was drawn into $10-\mathrm{ml}$ customized Cell Save Vacutainer tubes (Becton-Dickinson, New Jersey, U.S.), including EDTA and a cell fixative, followed by CTC enumeration within $72 \mathrm{~h}$. Reagents used included anti-epithelial cell adhesion molecule (anti-EpCAM) antibody-coated magnetic beads, fluorescent dye-labeled anti-CD45 antibody and anti-cytokeratins (CK-8, -18, and -19) antibody, and 4', 6-diamidino-2-phenylindole (DAPI). CTCs identified with the CellSearch system were CK-positive, DAPI-positive, and CD45-negative.

\section{Statistical analysis and illustrations}

Statistical analysis was performed using SPSS 18.0 software (SPSS Inc., Chicago, IL). Correlations of CTCs to clinicopathological characteristics were analyzed with Pearson's Chi Square or Fisher's exact test. Disease-free survival (DFS) was defined from the date of surgery to post-operative recurrence or death caused by any reason. Overall survival (OS) was defined from the date of surgery to death caused by any reason. Correlations of pre- and postoperative CTC counts to DFS or OS were analyzed using Kaplan-Meier tests. Crosstab was used to analyze the relationship between 3-year disease-free survival rate (3-year DFS) and CTCs in pre- and postsurgical blood or clinicopathological characteristics. A two-sided $\mathrm{p}<0.05$ was considered to be statistically significant. All of the illustrations were created by Photoshop CS4 (Adobe). 


\section{Results}

Patient characteristics

Patients $(n=93)$ with resectable gastric cancer were prospectively assessed. Patient characteristics are presented in Table 1 . In total, 68 male and 25 female patients were included in this study, with the median age of 60 years (26-82 years). Twenty-nine (31.2\%) patients had primary tumors located in gastroesophageal junction, and 71 patients $(76.3 \%)$ had tumors with poor differentiation (including low differentiation, mucinous adenocarcinoma, and signet-ring cell carcinoma). The number of patients with stage I, II,

Table 1 Characteristics of patients

\begin{tabular}{|c|c|c|}
\hline Characteristics & $\begin{array}{l}\text { Pre-operation }(n=93) \\
\text { No. of Patients }(\%)\end{array}$ & $\begin{array}{l}\text { Post-operation }(n=63) \\
\text { No. of Patients }(\%)\end{array}$ \\
\hline \multicolumn{3}{|l|}{ Gender } \\
\hline Male & $68(73.1 \%)$ & $46(73.0 \%)$ \\
\hline Female & 25 (26.9\%) & $17(27.0 \%)$ \\
\hline \multicolumn{3}{|l|}{ Age (years) } \\
\hline$\leq 45$ & $16(17.2 \%)$ & $13(20.6 \%)$ \\
\hline$>45$ & 77 (82.8\%) & $50(79.4 \%)$ \\
\hline \multicolumn{3}{|l|}{ Primary site ${ }^{\mathrm{a}}$} \\
\hline EGJ & $29(31.2 \%)$ & $19(30.2 \%)$ \\
\hline Non-EGJ & $64(68.8 \%)$ & $44(69.8 \%)$ \\
\hline \multicolumn{3}{|l|}{ Differentiation ${ }^{\mathrm{b}}$} \\
\hline Good & $22(23.7 \%)$ & $15(23.8 \%)$ \\
\hline Poor & $71(76.3 \%)$ & $48(76.2 \%)$ \\
\hline \multicolumn{3}{|l|}{ Lauren } \\
\hline Intestinal & $36(38.7 \%)$ & 25 (39.7\%) \\
\hline Diffuse & $23(24.7 \%)$ & $16(25.4 \%)$ \\
\hline Mixed & $34(36.6 \%)$ & $22(34.9 \%)$ \\
\hline \multicolumn{3}{|l|}{ TNM classification } \\
\hline I & $24(25.8 \%)$ & $15(23.8 \%)$ \\
\hline$\|$ & $24(25.8 \%)$ & $16(25.4 \%)$ \\
\hline III & 45 (48.4\%) & $32(50.8 \%)$ \\
\hline \multicolumn{3}{|c|}{ Depth of penetration } \\
\hline $\mathrm{T} 1 / \mathrm{T} 2$ & 30 (32.3\%) & $19(30.2 \%)$ \\
\hline $\mathrm{T} 3$ & $34(36.6 \%)$ & 25 (39.7\%) \\
\hline $\mathrm{T} 4$ & $29(31.2 \%)$ & $19(30.2 \%)$ \\
\hline \multicolumn{3}{|l|}{ Lymph node } \\
\hline NO & 31 (33.3\%) & $16(25.4 \%)$ \\
\hline N1/N2 & $31(33.3 \%)$ & $26(41.3 \%)$ \\
\hline N3 & $31(33.3 \%)$ & $21(33.3 \%)$ \\
\hline \multicolumn{3}{|c|}{ Lymph-vascular invasion } \\
\hline Yes & 45 (48.4\%) & $34(54.0 \%)$ \\
\hline No & $48(51.6 \%)$ & $29(46.0 \%)$ \\
\hline \multicolumn{3}{|c|}{ CEA ${ }^{\mathrm{C}}$ level before operation (ng/ml) } \\
\hline$<5$ & 75 (80.6\%) & $51(81.0 \%)$ \\
\hline$\geq 5$ & $17(18.3 \%)$ & $12(19.0 \%)$ \\
\hline$N A^{d}$ & $1(1.1 \%)$ & $0(0.0 \%)$ \\
\hline \multicolumn{3}{|c|}{ Adjuvant chemotherapy } \\
\hline Yes & $56(60.2 \%)$ & $42(66.7 \%)$ \\
\hline No & $37(39.8 \%)$ & $21(33.3 \%)$ \\
\hline
\end{tabular}

${ }^{a}$ EGJ, gastroesophageal junction

${ }^{\mathrm{b}}$ Good, including high or moderate differentiation; Poor, including low differentiation, mucinous adenocarcinoma, and signet-ring cell carcinoma

c carcinoembryonic antigen

d non-available 
and III were $24(25.8 \%), 24(25.8 \%)$, and $45(48.4 \%)$, respectively.

\section{Correlations of CTCs to clinicopathological characteristics}

For preoperation blood collection, $\geq 1, \geq 2, \geq 3, \geq 4$, and $\geq 5 \mathrm{CTCs} / 7.5 \mathrm{ml}$ were found in 31 (33.3\%), 13 (14.0\%), 9 (9.7\%), 6 (6.5\%), and 5 (5.4\%) patients, respectively. In addition, for postoperation blood collection, $\geq 1, \geq 2$, $\geq 3, \geq 4$, and $\geq 5$ CTCs $/ 7.5 \mathrm{ml}$ were found in 21 (33.3\%), 11 (17.5\%), 10 (15.9\%), 8 (12.7\%), and 4 (6.3\%) patients, respectively. Preoperative CTCs data are presented in Table 2 and Fig. 1. CTCs were significantly $(\mathrm{p}<0.05)$ correlated with Lauren, TNM classification, depth of penetration, and lymph-vascular invasion (Fig. 1a-d). However, there was no significant $(p>0.05)$ correlation between CTCs and age, differentiation, lymph node metastasis, and CEA levels prior to surgery (Fig. 1e-h). Moreover, patients no older than 45 years-of-age, with low differentiation and lymph node metastasis were more likely to have more CTCs. Additional file 1: Table S1 depicts patients CTCs data pre- and post-surgery. Postoperative CTCs were correlated with patient characteristics in a manner similar to pre-operative CTCs (Table 3). Patients with relatively poor clinicopathological features had more post-operative CTCs, and this was significantly correlated with depth of penetration $(\mathrm{p}<0.05)$ and nonsignificantly correlated with TNM classification $(\mathrm{p}>0.05$; Fig. 2). Ten patients had $\geq 3 \mathrm{CTCs} / 7.5 \mathrm{ml}$ in post-operative samples and most had poor differentiation $(\mathrm{n}=8)$, stage IIB/III $(n=10)$, or T3/T4 $(n=10)$ penetration.

\section{Correlations of CTCs enumeration with DFS and OS in resectable gastric cancer}

Until November 2016, median follow-up was 36.4 [interquartile 33.9-38.7] months. In total, 31 (33.3\%) patients relapsed, 24 (25.8\%) patients died. Patients CTC and DFS data are presented in Additional file 2: Table S2. In our study, patients with gastroesophageal junction, T3/T4 penetration, lymph node metastases, CEA level $\geq 5 \mathrm{ng} / \mathrm{ml}$ and higher pre- or postoperative CTCs had lower 3-year DFS (Table 2 and Fig. 3a). The 3-year DFS was $100.0 \%$ in patients with stage I tumors, $68.3 \%$ in patients with stage II tumors, $44.0 \%$ in patients with stage III tumors (Table 2). As shown in Fig. 3a, patients who had more CTCs had lower 3-year DFS. Obviously, as the threshold increased, the 3-year DFS of patients with post-operative CTCs above each cut-off value decreased markedly. Moreover, 3-year DFS in patients with CTCs $\geq 5 / 7.5 \mathrm{ml}$ was significantly lower than in patients with CTCs $<5 / 7.5 \mathrm{ml}$ (40.0\% vs $66.4 \%$, $\mathrm{p}<0.001$ for preoperation CTCs; $25.0 \%$ vs $62.2 \%, \mathrm{p}<0.001$ for postoperation CTCs; Fig. 3a). In addition, patients with $\geq 5$ CTCs $/ 7.5 \mathrm{ml}$ blood pre-operatively had shorter DFS $(\mathrm{p}=0.068)$ and OS $(\mathrm{p}=0.027)$ as assessed by univariate analyses (Fig. 3b, c). Likewise, patients with CTCs $\geq 5 / 7.5 \mathrm{ml}$ in postoperative blood had significantly shorter DFS (1.28 vs 31.6 months; $\mathrm{p}=0.002)$ and $\mathrm{OS}(10.0$ vs 34.9 months; $\mathrm{p}=0.001)$ than patients with CTCs $<5 / 7.5 \mathrm{ml}$ (Fig. 3d, e). These results indicated that postoperative CTCs may be an effective prognostic marker in resectable gastric cancer; therefore, more attention and proper adjuvant chemotherapy should be given to patients who have higher post-operative CTCs.

\section{Changes of CTCs during surgery to recurrence pattern}

Among the 31 patients who relapsed, 10 patients had hematogenous (osseous, hepatic and lung) metastases, and 14 patients had non-hematogenous (peritoneal and locoregional) metastases. The remaining seven patients had no identified hematogenous recurrence or nonhematogenous recurrence until death. We found that pre-operative CTCs were not correlated with the recurrence pattern (Additional file 3: Figure S1). Patients with hematogenous metastases who had post-operative CTCs $\geq 2 / 7.5 \mathrm{ml}$ had markedly shorter DFS (Fig. 4a). The DFS of three patients with hematogenous metastases who had markedly increased CTCs after surgery was short (1.1, 1.1, and 1.4 months, respectively, Fig. 4b); however, the DFS of other patients was relatively longer (25.9, 20.2, 11.9, 6.0, 30.0, 20.0 and 15.5 months, respectively). For patients with non-hematogenous metastases, the post-operative CTCs and changes of CTCs during surgery were not correlated with DFS. Post-operative CTC and markedly increased CTC during surgery may have potential association with hematogenous metastasis and suggest early recurrence.

\section{Discussion}

Surgery is the first-line therapy for gastric cancer, especially for patients with resectable gastric cancer; however, tumor recurrence within 5 years suggests a poor prognosis [2]. The 5-year DFS for patients with stage II, IIIA, and IIIB gastric cancer are $64.4,50.0$, and $34.4 \%$, respectively [2]. Poor clinicopathological features and high CEA and CA-19-9 tumor markers are risk factors for post-operative tumor recurrence, even though these markers have limited clinical significance [4-7]. Thus, there is a need to distinguish patients with high post-operative recurrence risk with effective biomarkers.

Recently, CTCs have been suggested to have utility as a predictor of chemotherapeutic response and prognosis, as CTCs can predict relapse-free survival in metastatic colorectal, prostate, and breast cancers [11-16]. For resectable gastric cancer, only one study reported that relapse-free survival was less common for patients with measurable pre-operative CTCs compared to those 
Table 2 Correlation of preoperative CTC number to clinicopathological characteristics

\begin{tabular}{|c|c|c|c|c|c|c|}
\hline \multirow[t]{2}{*}{ Characteristics } & \multirow{2}{*}{$\begin{array}{l}\text { 3-year recurrence } \\
\text { rate\% }\end{array}$} & \multicolumn{5}{|c|}{ No. of patients (\%) } \\
\hline & & $\mathrm{CTC} \geq 1 / 7.5 \mathrm{ml}$ & $\mathrm{CTC} \geq 2 / 7.5 \mathrm{ml}$ & $\mathrm{CTC} \geq 3 / 7.5 \mathrm{ml}$ & $\mathrm{CTC} \geq 4 / 7.5 \mathrm{ml}$ & $\mathrm{CTC} \geq 5 / 7.5 \mathrm{ml}$ \\
\hline \multicolumn{7}{|l|}{ Gender } \\
\hline Male $(n=68)$ & 65.6 & $23(33.8 \%)$ & $9(13.2 \%)$ & $6(8.8 \%)$ & $5(7.4 \%)$ & $5(7.4 \%)$ \\
\hline Female $(n=25)$ & 63.1 & $8(32.0 \%)$ & $4(16.0 \%)$ & $3(12.0 \%)$ & $1(4.0 \%)$ & $0(0.0 \%)$ \\
\hline$p$ value & 0.658 & 0.869 & 0.997 & 0.949 & 1.000 & 0.319 \\
\hline \multicolumn{7}{|l|}{ Age } \\
\hline$\leq 45(n=16)$ & 58.3 & $6(37.5 \%)$ & $4(25.0 \%)$ & $4(25.0 \%)$ & $2(12.5 \%)$ & $1(6.3 \%)$ \\
\hline$>45(n=77)$ & 66.2 & $25(32.5 \%)$ & $9(11.7 \%)$ & $5(6.5 \%)$ & $4(5.2 \%)$ & $4(5.2 \%)$ \\
\hline$p$ value & 0.244 & 0.698 & 0.317 & 0.070 & 0.274 & 1.000 \\
\hline \multicolumn{7}{|l|}{ Primary site ${ }^{a}$} \\
\hline$E G J(n=29)$ & 50.4 & $9(31.0 \%)$ & $3(10.3 \%)$ & $2(6.9 \%)$ & $2(6.9 \%)$ & $2(6.9 \%)$ \\
\hline Non-EGJ $(n=64)$ & 71.2 & $22(34.3 \%)$ & $10(15.6 \%)$ & $7(10.9 \%)$ & $4(6.3 \%)$ & $3(4.7 \%)$ \\
\hline$p$ value & 0.002 & 0.873 & 0.787 & 0.873 & 1.000 & 0.635 \\
\hline \multicolumn{7}{|l|}{ Differentiation ${ }^{b}$} \\
\hline Good $(n=22)$ & 71.8 & $4(18.2 \%)$ & $1(4.5 \%)$ & $1(4.5 \%)$ & $0(0.0 \%)$ & $0(0.0 \%)$ \\
\hline Poor $(n=71)$ & 62.6 & $27(38.0 \%)$ & $12(16.9 \%)$ & $8(11.3 \%)$ & $6(8.5 \%)$ & $5(7.0 \%)$ \\
\hline$p$ value & 0.174 & 0.084 & 0.268 & 0.604 & 0.330 & 0.335 \\
\hline \multicolumn{7}{|l|}{ Lauren } \\
\hline Intestinal $(n=36)$ & 68.0 & $8(22.2 \%)$ & $2(5.6 \%)$ & $1(2.8 \%)$ & $0(0.0 \%)$ & $0(0.0 \%)$ \\
\hline Diffuse $(n=23)$ & 67.4 & $6(26.1 \%)$ & $5(21.7 \%)$ & $5(21.7 \%)$ & $3(13.0 \%)$ & $2(8.7 \%)$ \\
\hline Mixed $(n=34)$ & 60.0 & $17(50.0 \%)$ & $6(17.6 \%)$ & $3(8.8 \%)$ & $3(8.8 \%)$ & $3(8.8 \%)$ \\
\hline$p$ value & 0.434 & 0.033 & 0.118 & 0.060 & 0.068 & 0.148 \\
\hline \multicolumn{7}{|l|}{ TNM classification } \\
\hline $\mathrm{I}(\mathrm{n}=24)$ & 100.0 & $6(25.0 \%)$ & $0(0.0 \%)$ & $0(0.0 \%)$ & $0(0.0 \%)$ & $0(0.0 \%)$ \\
\hline$\|(n=24)$ & 68.3 & $8(33.3 \%)$ & $4(16.7 \%)$ & $2(8.3 \%)$ & $1(4.2 \%)$ & $1(4.2 \%)$ \\
\hline III $(n=45)$ & 44.0 & $17(37.8 \%)$ & $9(20.0 \%)$ & $7(15.6 \%)$ & $5(11.1 \%)$ & $4(8.9 \%)$ \\
\hline$p$ value & 0.000 & 0.563 & 0.047 & 0.103 & 0.306 & 0.443 \\
\hline \multicolumn{7}{|l|}{ Depth of penetration } \\
\hline$T 1 / T 2(n=30)$ & 90.0 & $8(26.7 \%)$ & $1(3.3 \%)$ & $1(3.3 \%)$ & $1(3.3 \%)$ & $1(3.3 \%)$ \\
\hline T3 $(n=34)$ & 56.9 & $12(35.3 \%)$ & $5(14.7 \%)$ & $1(2.9 \%)$ & $0(0.0 \%)$ & $0(0.0 \%)$ \\
\hline $\mathrm{T} 4(\mathrm{n}=29)$ & 47.7 & $11(37.9 \%)$ & $7(24.1 \%)$ & $7(24.1 \%)$ & $5(17.2 \%)$ & $4(13.8 \%)$ \\
\hline$p$ value & 0.000 & 0.627 & 0.064 & 0.007 & 0.009 & 0.026 \\
\hline \multicolumn{7}{|l|}{ Lymph node } \\
\hline No $(n=31)$ & 96.8 & $7(22.6 \%)$ & $2(6.5 \%)$ & $1(3.2 \%)$ & $0(0.0 \%)$ & $0(0.0 \%)$ \\
\hline $\mathrm{N} 1 / \mathrm{N} 2(\mathrm{n}=31)$ & 58.4 & $9(29.0 \%)$ & $3(9.7 \%)$ & $2(6.5 \%)$ & $2(6.5 \%)$ & $2(6.5 \%)$ \\
\hline$N 3(n=31)$ & 38.9 & $15(48.4 \%)$ & $8(25.8 \%)$ & $6(19.4 \%)$ & $4(12.9 \%)$ & $3(9.7 \%)$ \\
\hline$p$ value & 0.000 & 0.081 & 0.109 & 0.133 & 0.160 & 0.362 \\
\hline \multicolumn{7}{|c|}{ Lymph-vascular invasion } \\
\hline Yes $(n=45)$ & 53.0 & $20(44.4 \%)$ & $9(20.0 \%)$ & $6(13.3 \%)$ & $3(6.7 \%)$ & $3(6.7 \%)$ \\
\hline No $(n=48)$ & 75.8 & $11(22.9 \%)$ & $4(8.3 \%)$ & $3(6.3 \%)$ & $3(6.3 \%)$ & $2(4.2 \%)$ \\
\hline$p$ value & 0.001 & 0.028 & 0.105 & 0.307 & 1.000 & 0.671 \\
\hline \multicolumn{7}{|c|}{ CEA $^{c}$ level before operation (ng/ml) } \\
\hline$<5(n=75)$ & 68.8 & $26(34.7 \%)$ & $12(16.0 \%)$ & $9(12.0 \%)$ & $6(8.0 \%)$ & $5(6.7 \%)$ \\
\hline$\geq 5(n=17)$ & 46.3 & $5(29.4 \%)$ & $1(5.9 \%)$ & $0(0.0 \%)$ & $0(0.0 \%)$ & $0(0.0 \%)$ \\
\hline $\mathrm{NA}^{\mathrm{d}}(\mathrm{n}=1)$ & & $0(0.0 \%)$ & $0(0.0 \%)$ & $0(0.0 \%)$ & $0(0.0 \%)$ & $0(0.0 \%)$ \\
\hline$P$ value & 0.001 & 0.679 & 0.487 & 0.293 & 0.589 & 0.580 \\
\hline
\end{tabular}

Italic values indicate that there are significant differences in pre-operative CTCs between different clinicopathological types

${ }^{a}$ EGJ, gastroesophageal junction

b Good, including high or moderate differentiation; Poor, including low differentiation, mucinous adenocarcinoma, and signet-ring cell carcinoma

c carcinoembryonic antigen

d non-available 


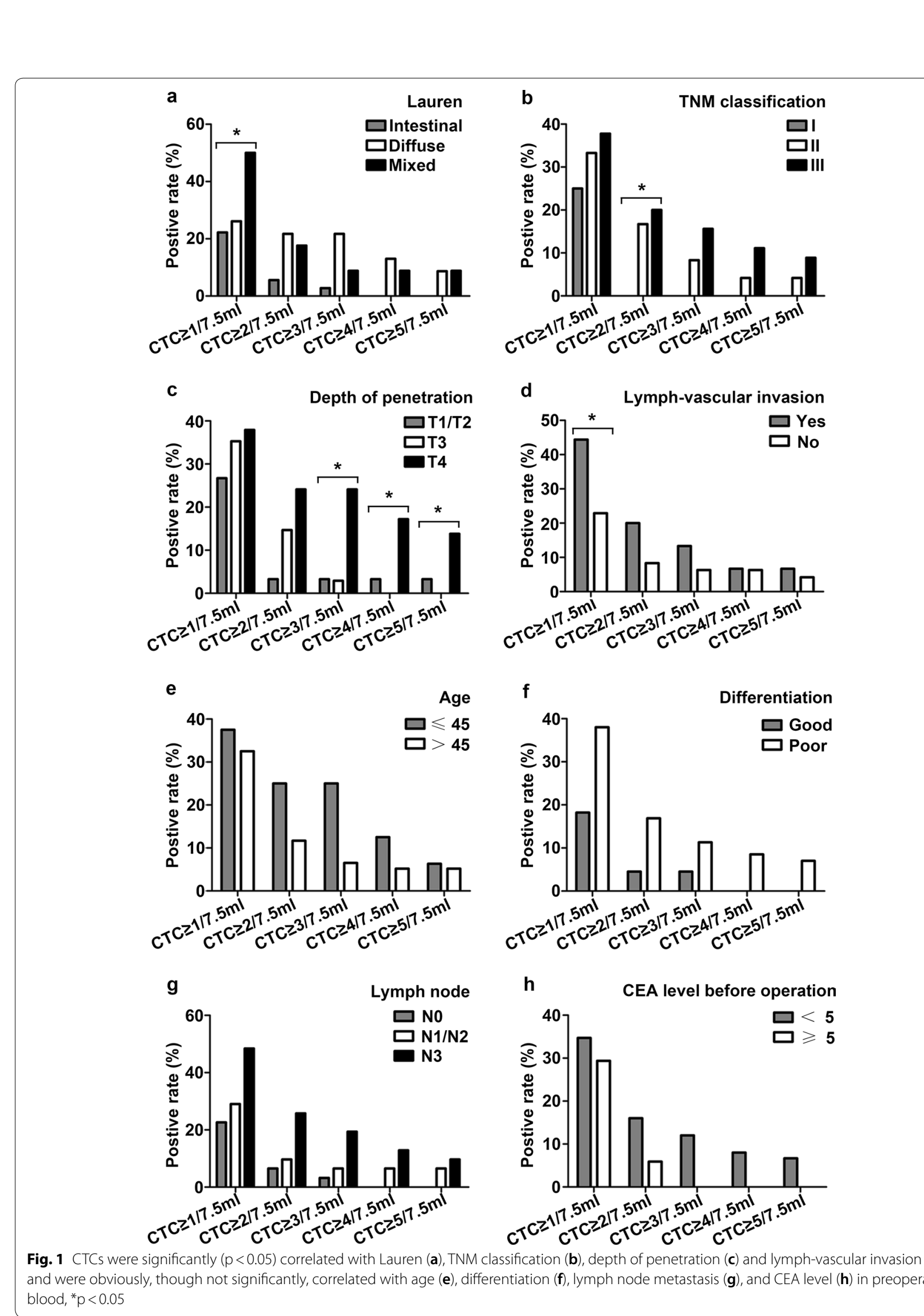



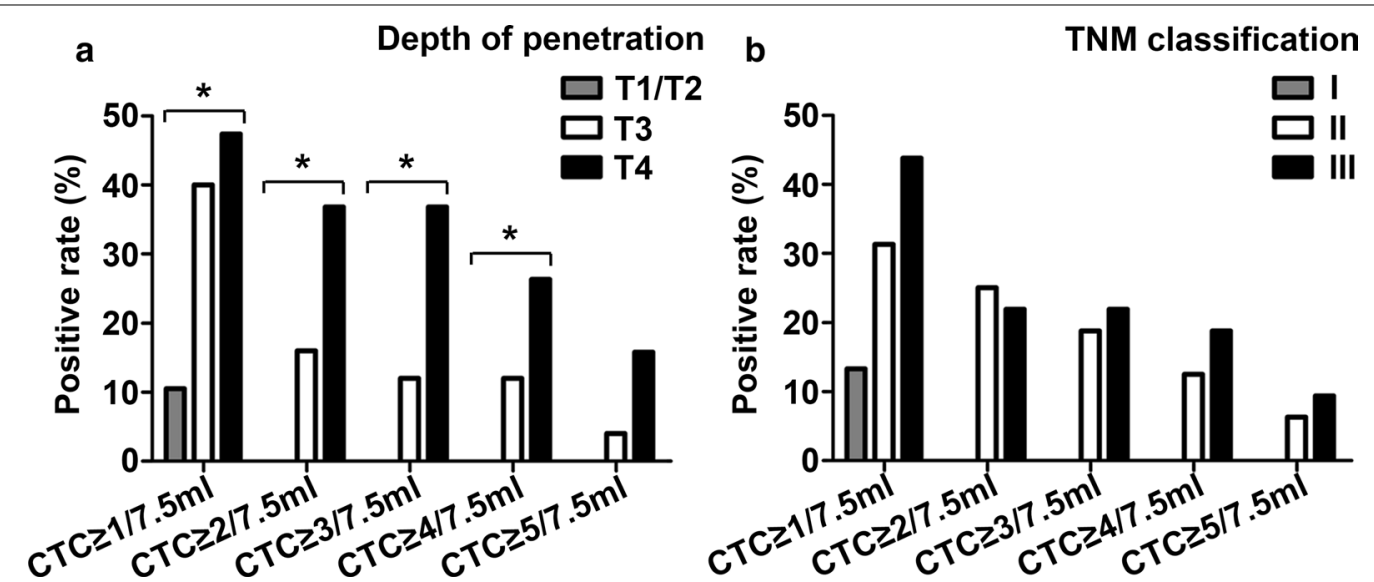

Fig. 2 CTCs were significantly $(p<0.05)$ correlated with depth of penetration (a) and were obviously, though not significantly, correlated with TNM classification (b) in postoperative blood, ${ }^{*} p<0.05$

with non-detectable CTCs [23]. Therefore, we measured pre- and post-operative CTCs and changes in CTCs during surgery in patients with resectable gastric cancer and correlated these changes with clinicopathological features, post-operative tumor recurrence, and recurrence patterns.

Circulating tumor cells measured in 31 patients prior to surgery were greater than those reported in another study using a prospective cohort [23]. Differences in clinicopathological features between our and other cohorts may explain this discrepancy, such as differences in TNM classification and depth of tumor penetration. In our study, 63 patients had paired pre- and post-operative samples and CTCs were found in 21 patients postoperatively. These data demonstrated that CTCs may still appear in circulation after radical surgery. Thus, longterm monitoring CTCs after surgery may predict postoperative tumor recurrence.

Patients with relatively poor clinicopathological features had greater pre- and post-operative CTCs. Poor clinicopathological features were correlated with high post-operative tumor recurrence risk and poor prognosis, suggesting that patients with higher pre- or postoperative CTCs had earlier recurrence. Until now, studies of correlations in CTCs with recurrence of resectable gastric cancer have been limited, so there is no standard threshold. To address this issue, we set CTC counts of 1 , $2,3,4$, and 5 as thresholds and found that patients with pre-surgical CTCs $\geq 4$ had obviously but not significantly shorter DFS $(p=0.459)$ and OS $(p=0.209)$ than patients without CTC or patients with 1-3 CTCs (Additional file 4: Figure S2). The median DFS of patients without CTC, 1-3 CTCs, or more than 4 CTCs post-operatively were $33.87,34.33$, and 20.98 months respectively. As the threshold increased, we observed that pre-surgical
CTCs $\geq 5$ were significantly associated with worse outcomes (Fig. 3a-e). For this reason, we set 5 as the threshold value.

Since the prognostic value of pre-operative CTCs is likely to be affected by surgery, we suggest that postoperative CTCs might be a more direct and efficient recurrence marker than pre-operative CTCs. However, few reports have questioned whether monitoring postoperative CTCs is useful for predicting prognosis. Our results demonstrated that patients with post-operative CTCs $\geq 4-5$ had shorter DFS, OS, and less 3-years DFS (Fig. 3a-e, Additional file 4: Figure S2). In addition, acting as the "seed" of hematogenous metastasis, CTCs can travel in the circulation and form metastases $[9,10]$. High post-operative CTCs and markedly increased post-operative CTCs were correlated with hematogenous metastasis, while pre-operative CTCs were not correlated with recurrence patterns. Our results also confirmed that post-operative CTCs might be a more direct post-operative recurrence marker especially for patients who experienced hematogenous recurrence. As a result, monitoring the recurrence patterns of gastric cancer is important for better post-operative adjuvant treatment decisions.

There are several limitations in our study. First, our study aimed to analyze the clinical significance of CTCs in radical gastric cancer, and patients with stage I and II accounted for $51.6 \%$ of all of the patients. Furthermore, CTCs $\geq 3-5$ were identified in a few patients. For future work, more subjects are needed to determine an optimal threshold, and a sufficient sample size to adequately perform Kaplan-Meier analyses. Second, mesenchymal-like cancer cells are likely to escape from CellSearch system detection, which is based on epithelial markers, such as EpCAM and CKs [17]. Nonetheless, in future studies, we can 
Table 3 Correlation of postoperative CTC number to clinicopathological characteristics

\begin{tabular}{|c|c|c|c|c|c|c|}
\hline \multirow[t]{2}{*}{ Characteristics } & \multirow{2}{*}{$\begin{array}{l}\text { 3-year } \\
\text { recurrence } \\
\text { rate } \%\end{array}$} & \multicolumn{5}{|c|}{ No. of patients (\%) } \\
\hline & & $\mathrm{CTC} \geq 1 / 7.5 \mathrm{ml}$ & $\mathrm{CTC} \geq 2 / 7.5 \mathrm{ml}$ & $\mathrm{CTC} \geq 3 / 7.5 \mathrm{ml}$ & $\mathrm{CTC} \geq 4 / 7.5 \mathrm{ml}$ & $\mathrm{CTC} \geq 5 / 7.5 \mathrm{ml}$ \\
\hline \multicolumn{7}{|l|}{ Gender } \\
\hline Male $(n=46)$ & 60.9 & $18(39.1 \%)$ & $10(21.7 \%)$ & $9(19.6 \%)$ & $7(15.2 \%)$ & $3(6.5 \%)$ \\
\hline Female $(n=17)$ & 57.5 & $3(17.6 \%)$ & $1(5.9 \%)$ & $1(5.9 \%)$ & $1(5.9 \%)$ & $1(5.9 \%)$ \\
\hline$p$ value & 0.606 & 0.108 & 0.272 & 0.352 & 0.574 & 1.000 \\
\hline \multicolumn{7}{|l|}{ Age } \\
\hline$\leq 45(n=13)$ & 57.1 & $5(38.5 \%)$ & $2(15.4 \%)$ & $2(15.4 \%)$ & $2(15.4 \%)$ & $1(7.7 \%)$ \\
\hline$>45(n=50)$ & 60.6 & $16(32.0 \%)$ & $9(18.0 \%)$ & $8(16.0 \%)$ & $6(12.0 \%)$ & $3(6.0 \%)$ \\
\hline$p$ value & 0.565 & 0.912 & 1.000 & 1.000 & 1.000 & 1.000 \\
\hline \multicolumn{7}{|l|}{ Primary site ${ }^{\mathrm{a}}$} \\
\hline EGJ $(n=19)$ & 43.5 & $7(36.8 \%)$ & $3(15.8 \%)$ & $3(15.8 \%)$ & $3(15.8 \%)$ & $1(5.3 \%)$ \\
\hline Non-EGJ $(n=44)$ & 67.2 & $14(31.8 \%)$ & $8(18.2 \%)$ & $7(15.9 \%)$ & $5(11.4 \%)$ & $3(6.8 \%)$ \\
\hline$p$ value & 0.001 & 0.698 & 1.000 & 1.000 & 0.943 & 1.000 \\
\hline \multicolumn{7}{|l|}{ Differentiation ${ }^{b}$} \\
\hline Good $(n=15)$ & 66.0 & $5(33.3 \%)$ & $3(20.0 \%)$ & $2(13.3 \%)$ & $1(6.7 \%)$ & $0(0.0 \%)$ \\
\hline Poor $(n=48)$ & 57.8 & $16(33.3 \%)$ & $8(16.7 \%)$ & $8(16.7 \%)$ & $7(14.6 \%)$ & $4(8.3 \%)$ \\
\hline$p$ value & 0.244 & 1.000 & 1.000 & 1.000 & 0.719 & 0.564 \\
\hline \multicolumn{7}{|l|}{ Lauren } \\
\hline Intestinal $(n=25)$ & 62.0 & $8(32.0 \%)$ & $5(20.0 \%)$ & $4(16.0 \%)$ & $2(8.0 \%)$ & $0(0.0 \%)$ \\
\hline Diffuse $(n=16)$ & 65.7 & $4(25.0 \%)$ & $3(18.8 \%)$ & $3(18.8 \%)$ & $3(18.8 \%)$ & $2(12.5 \%)$ \\
\hline Mixed $(n=22)$ & 52.4 & $9(40.9 \%)$ & $3(13.6 \%)$ & $3(13.6 \%)$ & $3(13.6 \%)$ & $2(9.1 \%)$ \\
\hline$p$ value & 0.115 & 0.580 & 0.844 & 0.913 & 0.505 & 0.167 \\
\hline \multicolumn{7}{|l|}{ TNM classification } \\
\hline I $(n=15)$ & 100.0 & $2(13.3 \%)$ & $0(0.0 \%)$ & $0(0.0 \%)$ & $0(0.0 \%)$ & $0(0.0 \%)$ \\
\hline$\|(n=16)$ & 54.7 & $5(31.3 \%)$ & $4(25.0 \%)$ & $3(18.8 \%)$ & $2(12.5 \%)$ & $1(6.3 \%)$ \\
\hline III $(n=32)$ & 43.1 & $14(43.8 \%)$ & 7 (21.9\%) & 7 (21.9\%) & $6(18.8 \%)$ & $3(9.4 \%)$ \\
\hline$p$ value & 0.062 & 0.117 & 0.106 & 0.161 & 0.249 & 0.798 \\
\hline \multicolumn{7}{|c|}{ Depth of penetration } \\
\hline$T 1 / T 2(n=19)$ & 89.5 & $2(10.5 \%)$ & $0(0.0 \%)$ & $0(0.0 \%)$ & $0(0.0 \%)$ & $0(0.0 \%)$ \\
\hline$T 3(n=25)$ & 51.2 & $10(40.0 \%)$ & $4(16.0 \%)$ & $3(12.0 \%)$ & $3(12.0 \%)$ & $1(4.0 \%)$ \\
\hline $\mathrm{T} 4(\mathrm{n}=19)$ & 41.4 & $9(47.4 \%)$ & $7(36.8 \%)$ & $7(36.8 \%)$ & $5(26.3 \%)$ & $3(15.8 \%)$ \\
\hline$p$ value & 0.000 & 0.036 & 0.008 & 0.005 & 0.043 & 0.178 \\
\hline \multicolumn{7}{|l|}{ Lymph node } \\
\hline No $(n=16)$ & 100.0 & $4(25.0 \%)$ & $2(12.5 \%)$ & $1(6.3 \%)$ & $0(0.0 \%)$ & $0(0.0 \%)$ \\
\hline$N 1 / N 2(n=26)$ & 54.5 & $8(30.8 \%)$ & $6(23.1 \%)$ & $6(23.1 \%)$ & $5(19.2 \%)$ & $2(7.7 \%)$ \\
\hline N3 $(n=21)$ & 33.3 & $9(42.9 \%)$ & $3(14.3 \%)$ & $3(14.3 \%)$ & $3(14.3 \%)$ & $2(9.5 \%)$ \\
\hline$p$ value & 0.001 & 0.488 & 0.761 & 0.375 & 0.185 & 0.663 \\
\hline \multicolumn{7}{|c|}{ Lymph-vascular invasion } \\
\hline Yes $(n=34)$ & 49.8 & $10(29.4 \%)$ & $5(14.7 \%)$ & $5(14.7 \%)$ & $3(8.8 \%)$ & $2(5.9 \%)$ \\
\hline No $(n=29)$ & 71.4 & $11(37.9 \%)$ & $6(20.7 \%)$ & $5(17.2 \%)$ & $5(17.2 \%)$ & $2(6.9 \%)$ \\
\hline$p$ value & 0.002 & 0.475 & 0.533 & 1.000 & 0.453 & 1.000 \\
\hline \multicolumn{7}{|c|}{ CEAc level before operation ( $\mathrm{ng} / \mathrm{ml}$ ) } \\
\hline$<5(\mathrm{n}=51)$ & 62.6 & $18(35.3 \%)$ & $9(17.6 \%)$ & $9(17.6 \%)$ & $8(15.7 \%)$ & $4(7.8 \%)$ \\
\hline$\geq 5(n=12)$ & 48.6 & $3(25.0 \%)$ & $2(16.7 \%)$ & $1(8.3 \%)$ & $0(0.0 \%)$ & $0(0.0 \%)$ \\
\hline$p$ value & 0.046 & 0.734 & 1.000 & 0.722 & 0.324 & 1.000 \\
\hline
\end{tabular}

Italic values indicate that there are significant differences in post-operative CTCs between different clinicopathological types

a $E G J$, gastroesophageal junction

b Good, including high or moderate differentiation; Poor, including low differentiation, mucinous adenocarcinoma, and signet-ring cell carcinoma

c carcinoembryonic antigen 


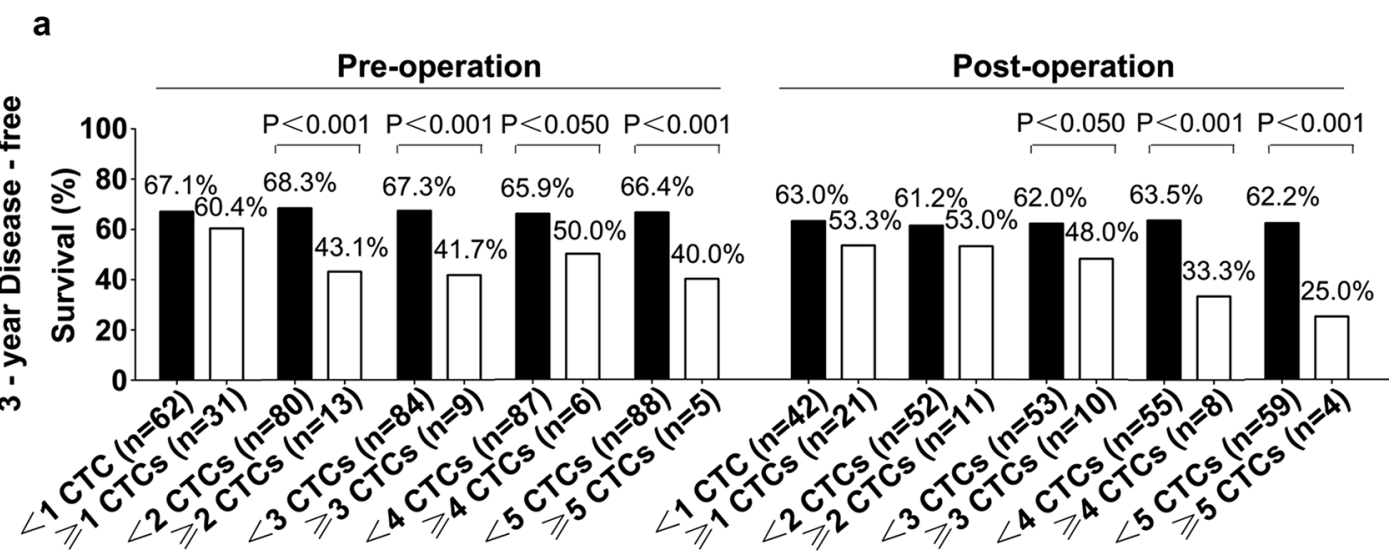

\section{Pre - operation CTCs}

b

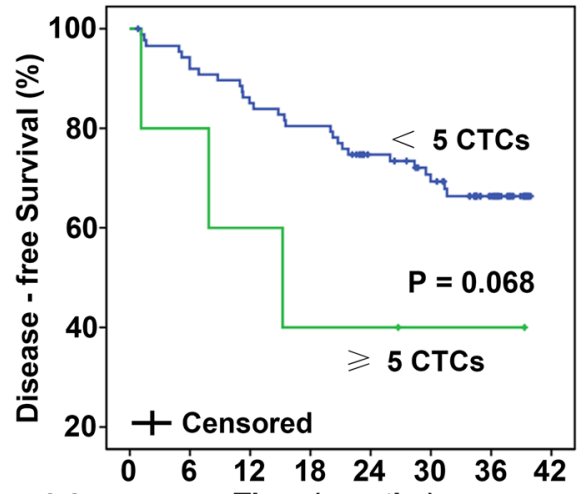

No. at risk Time (months)

c

\begin{tabular}{lllllllll}
\hline CTCs & 88 & 80 & 74 & 70 & 58 & 50 & 31
\end{tabular}

$\begin{array}{llllllll}\geqslant 5 \text { CTCs } & 5 & 4 & 3 & 2 & 2 & 1 & 1\end{array}$

Post - operation CTCs

d

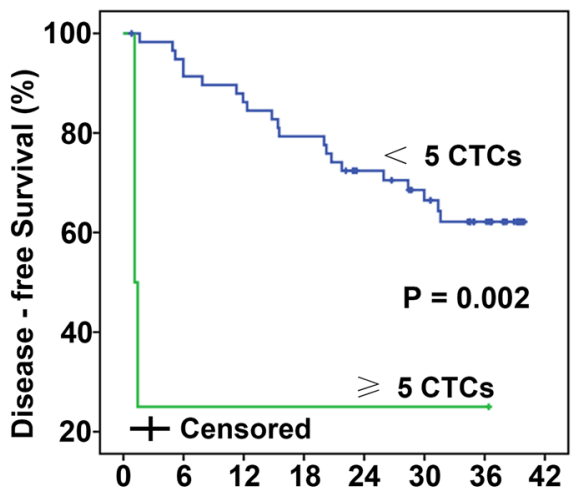

No. at risk Time (months)

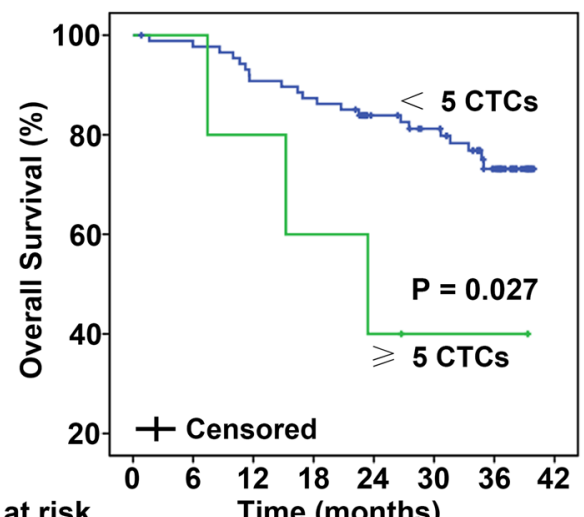

No. at risk Time (months)

\begin{tabular}{lllllllll}
\hline 5 CTCs & 88 & 85 & 79 & 76 & 64 & 58 & 36
\end{tabular}

$\begin{array}{llllllll}\geqslant 5 \mathrm{CTCs} & 5 & 5 & 4 & 3 & 2 & 1 & 1\end{array}$

e

\begin{tabular}{llllllll}
\hline 5 CTCs & 59 & 53 & 50 & 46 & 38 & 32 & 23
\end{tabular}

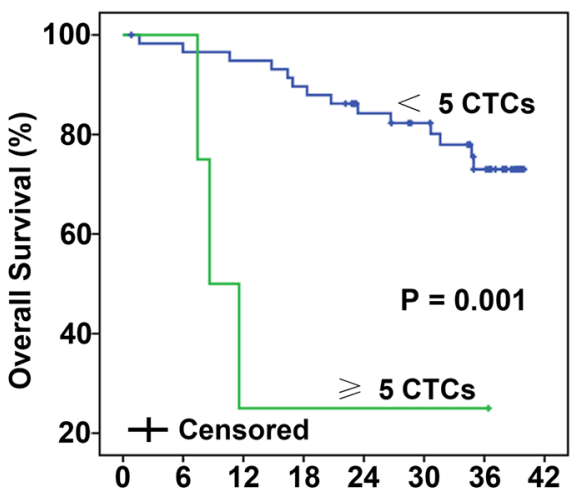

No. at risk

Time (months)

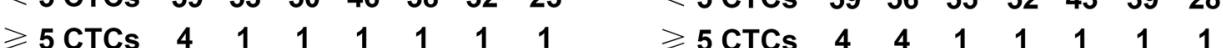

Fig. 3 3-year DFS was lower in patients who had more CTCS (a), the filled black columns represent the 3-year DFS of patients who had CTCs no more than the cut-off value, and the empty white columns represent 3-year DFS of patients who had CTC more than the cutoff value. Patients who have $\geq 5$ CTCS/7.5 ml blood pre-operatively had shorter DFS (b, d) and OS (c, e) 

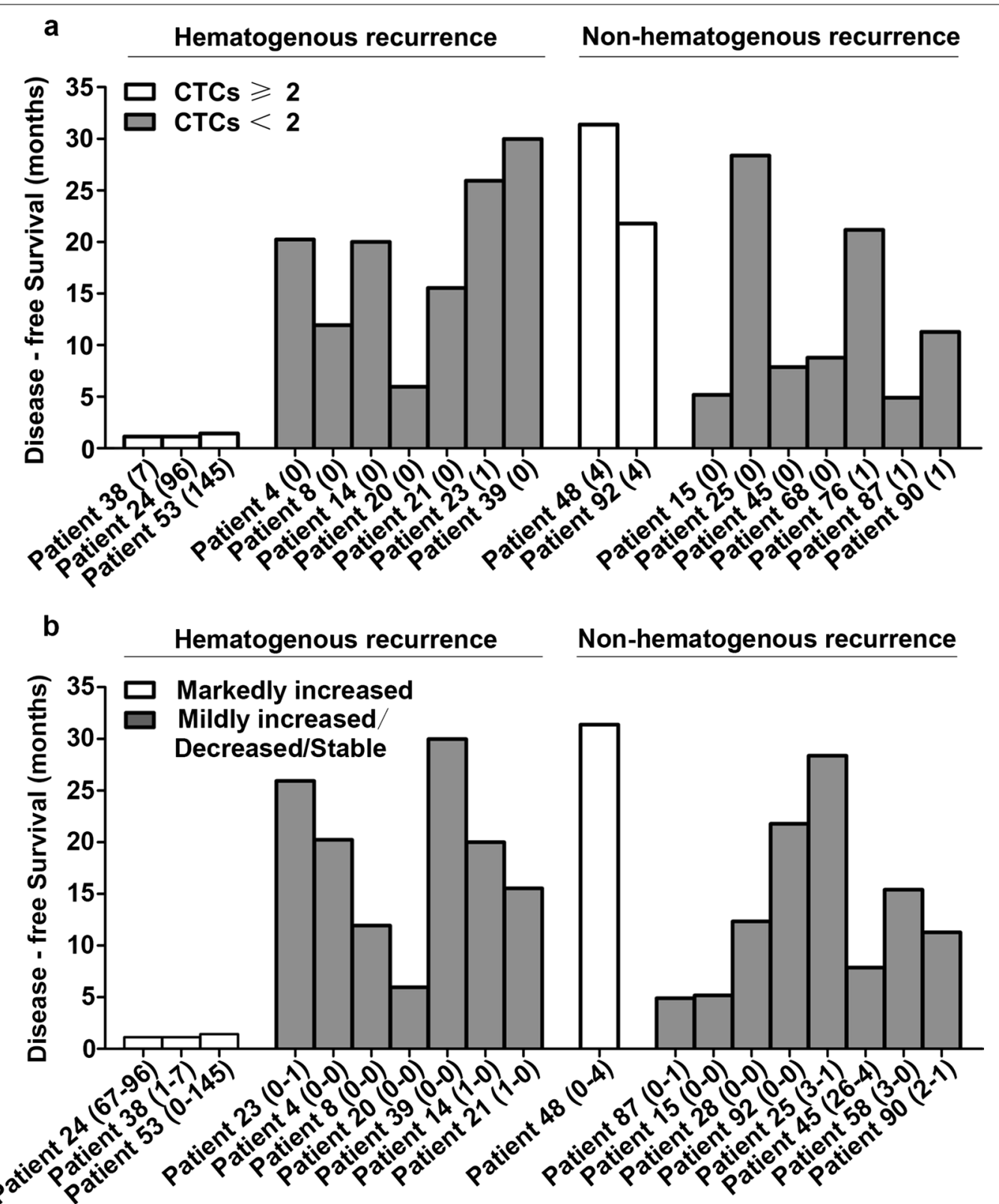

Fig. 4 Among hematogenous metastases subjects, patients who had post-operative CTCs $\geq 2 / 7.5 \mathrm{ml}$ (a) and patients who had markedly increased CTCs after surgery (b) had markedly shorter DFS

combine other methods of molecular analysis to better identify the prognostic value of CTCs in resectable gastric cancer. Third, numerous studies agree that intra-operative CTCs shedding occurs with tumor manipulation [24]. However, our data suggested that post-operative CTC enumeration within 1 week after surgery was not increased by surgery. Although intraoperative CTCs were not detected in our study, studies of other tumors reported that CTC detection rate and not CTC enumeration increased in intra-operative samples [24]. Moreover, studies also demonstrated that increased intra-operative CTCs normalize postoperatively within days to weeks [24]. Fourth, we collected post-operative samples within 1 week after surgery (2-7 days after surgery). We are also interested in how CTCs can change when the length of observation is increased to two or 3 weeks, which we will address in follow-up studies. Interestingly, Krag and colleagues reported that CTCs rapidly declined during $48 \mathrm{~h}$ post-operatively in most patients with operable 
breast cancer [25]. Animal studies also found the similar phenomenon [26]. Krag et al. also demonstrated that $30 \%$ patients had detectable CTCs persistently up to 14 days after surgery. These results are consistent with the notion that only a minority of CTCs can survive and have capacity to be clonogenic. In addition, those authors further put forward a view, which is similar to us, namely, the persistent presence of cancer cells after radical surgery is a strong indicator of recurrence. Therefore, we hypothesize that CTCs are stable from 2 days to 2 weeks, and CTCs should be monitored before and after surgery to predict cancer recurrence and for disease staging and treatment management.

\section{Conclusion}

In summary, we analyzed the utility of post-operative CTCs in resectable gastric cancer. In addition, to the best of our knowledge, this is the first prospective study that has analyzed the correlations between postoperative CTCs and changes in CTCs during surgery with clinicopathological characteristics, prognosis, and recurrence patterns. We found that post-operative CTCs might be a more direct and efficient recurrence marker than pre-operative CTCs and increased post-operative CTCs might be correlated with hematogenous recurrence. Monitoring the post-operative CTCs and changes in CTCs during surgery is of great importance for better post-operative adjuvant treatment decisions.

\section{Additional files}

Additional file 1: Table S1. Patient characteristics and CTC numbers in
63 patients.

Additional file 2: Table S2. Patient characteristics and CTC numbers in 31 relapsed patients.

Additional file 3: Figure S1. Correlations of pre-operative CTCs with patient recurrence patterns.

Additional file 4: Figure S2. Patients who have $\geq 4$ CTCS $/ 7.5 \mathrm{ml}$ blood pre-operatively had shorter DFS $(a, c)$ and OS $(b, d)$.

\section{Abbreviations \\ CTC: circulating tumor cell; CEA: carcinoembryonic antigen; OS: overall survival; EpCAM: epithelial cell adhesion molecule; CK: cytokeratin; DAPI: 4', 6-diamidino-2-phenylindole; DFS: disease-free survival; 3-year DFS: 3-year disease-free survival rate.}

\section{Authors' contributions}

ML designed the study. QZ and FS summarized the data and drafted the manuscript. All of the authors contributed to the revision of manuscript. All authors read and approved the final manuscript.
Acknowledgements

We thank LetPub for its linguistic assistance during the preparation of this manuscript.

\section{Competing interests}

The authors declare that they have no competing interests.

\section{Availability of data}

The data sets analyzed within the current study are available from the corresponding author upon reasonable request.

\section{Consent for publication}

Not applicable.

\section{Ethics approval and consent to participate}

All of the procedures followed were in accordance with the ethical standards of the responsible committee on human experimentation (institutional and national) and with the Helsinki Declaration of 1964 and later versions. Informed consent or an appropriate substitute was obtained from all of the patients prior to inclusion in the study.

\section{Funding}

This work was funded by Capital Health Research and Development (No. 2014-4-1023), the Beijing Natural Science Foundation (7161002), and the Beijing Municipal Administration of Hospital Clinical Medicine Development of Special Funding Support (ZYLX201701).

\section{Publisher's Note}

Springer Nature remains neutral with regard to jurisdictional claims in published maps and institutional affiliations.

Received: 26 January 2018 Accepted: 7 June 2018

Published online: 20 June 2018

\section{References}

1. Siegel R, Ma J, Zou Z, Jemal A. Cancer statistics, 2014. CA Cancer J Clin. 2014;64:9-29.

2. Sasako M, Sakuramoto S, Katai H, et al. Five-year outcomes of a randomized phase III trial comparing adjuvant chemotherapy with S-1 versus surgery alone in stage II or III gastric cancer. J Clin Oncol. 2011;29:4387-93.

3. Park SH, Sohn TS, Lee J, et al. Phase III trial to compare adjuvant chemotherapy with capecitabine and cisplatin versus concurrent chemoradiotherapy in gastric cancer: final report of the adjuvant chemoradiotherapy in stomach tumors trial, including survival and subset analyses. J Clin Oncol. 2015;33:3130-6.

4. Sun Z, Wang ZN, Zhu Z, et al. Evaluation of the seventh edition of American Joint Committee on Cancer TNM staging system for gastric cancer: results from a Chinese monoinstitutional study. Ann Surg Oncol. 2012;19:1918-27.

5. Li Z, Zou X, Xie L, et al. Personalizing risk stratification by addition of PAK1 expression to TNM staging: improving the accuracy of clinical decision for gastroesophageal junction adenocarcinoma. Int J Cancer. 2015;136:1636-45.

6. Duffy MJ, Lamerz R, Haglund C, et al. Tumor markers in colorectal cancer, gastric cancer and gastrointestinal stromal cancers: european group on tumor markers 2014 guidelines update. Int J Cancer. 2014;134:2513-22.

7. Cristescu R, Lee J, Nebozhyn M, et al. Molecular analysis of gastric cancer identifies subtypes associated with distinct clinical outcomes. Nat Med. 2015:21:449-56.

8. Yoo CH, Noh SH, Shin DW, Choi SH, Min JS. Recurrence following curative resection for gastric carcinoma. Br J Surg. 2000;87:236-42.

9. Reymond N, d'Água BB, Ridley AJ. Crossing the endothelial barrier during metastasis. Nat Rev Cancer. 2013;13:858-70.

10. Aceto N, Bardia A, Miyamoto DT, et al. Circulating tumor cell clusters are oligoclonal precursors of breast cancer metastasis. Cell. 2014;158:1110-22. 
11. Cristofanilli M, Budd GT, Ellis MJ, et al. Circulating tumor cells, disease progression, and survival in metastatic breast cancer. N Engl J Med. 2004;351:781-91.

12. Cohen $\mathrm{SJ}$, Punt $\mathrm{CJ}$, lannotti $\mathrm{N}$, et al. Relationship of circulating tumor cells to tumor response, progression-free survival, and overall survival in patients with metastatic colorectal cancer. J Clin Oncol. 2008;26:3213-21.

13. de Bono JS, Scher HI, Montgomery RB, et al. Circulating tumor cells predict survival benefit from treatment in metastatic castration-resistant prostate cancer. Clin Cancer Res. 2008:14:6302-9.

14. Krebs MG, Sloane R, Priest L, et al. Evaluation and prognostic significance of circulating tumor cells in patients with non-small-cell lung cancer. J Clin Oncol. 2011:29:1556-63.

15. Yu M, Bardia A, Aceto N, et al. Cancer therapy. Ex vivo culture of circulating breast tumor cells for individualized testing of drug susceptibility. Science. 2014;345:216-20.

16. Liu MC, Shields PG, Warren RD, et al. Circulating tumor cells: a useful predictor of treatment efficacy in metastatic breast cancer. J Clin Oncol. 2009;27:5153-9.

17. LiY, Zhang X, Ge S, et al. Clinical significance of phenotyping and karyotyping of circulating tumor cells in patients with advanced gastric cancer. Oncotarget. 2014;5:6594-602.

18. Sotelo MJ, Sastre J, Maestro ML, et al. Role of circulating tumor cells as prognostic marker in resected stage III colorectal cancer. Ann Oncol. 2015;26:535-41.
19. linuma H, Watanabe T, Mimori K, et al. Clinical significance of circulating tumor cells, including cancer stem-like cells, in peripheral blood for recurrence and prognosis in patients with Dukes' stage B and C colorectal cancer. J Clin Oncol. 2011;29:1547-55.

20. Lucci A, Hall CS, Lodhi AK, et al. Circulating tumour cells in non-metastatic breast cancer: a prospective study. Lancet Oncol. 2012;13:688-95.

21. Gazzaniga P, de Berardinis E, Raimondi C, et al. Circulating tumor cells detection has independent prognostic impact in high-risk non-muscle invasive bladder cancer. Int J Cancer. 2014;135:1978-82.

22. Pal SK, He M, Wilson T, et al. Detection and phenotyping of circulating tumor cells in high-risk localized prostate cancer. Clin Genitourin Cancer. 2015;13:130-6

23. Uenosono Y, Arigami T, Kozono T, et al. Clinical significance of circulating tumor cells in peripheral blood from patients with gastric cancer. Cancer. 2013;119:3984-91.

24. Kauffman EC, Lee MJ, Alarcon SV, et al. Lack of impact of robotic-assisted laparoscopic radical prostatectomy on intraoperative levels of prostate cancer circulating tumor cells. J Urol. 2015;195:1136-42.

25. Krag DN, Ashikaga T, Moss TJ, et al. Breast cancer cells in the blood: a pilot study. Breast J. 1999:5:354-8.

26. Butler TP, Gullino PM. Quantitation of cell shedding into efferent blood of mammary adenocarcinoma. Cancer Res. 1975;35:512-6.
Ready to submit your research? Choose BMC and benefit from:

- fast, convenient online submission

- thorough peer review by experienced researchers in your field

- rapid publication on acceptance

- support for research data, including large and complex data types

- gold Open Access which fosters wider collaboration and increased citations

- maximum visibility for your research: over 100M website views per year

At BMC, research is always in progress.

Learn more biomedcentral.com/submissions 